\title{
Radiological Imaging Findings of Avalanche Victims
}

\section{With Traumatic Lesions In Van Eastern Province of}

\section{Turkey}

\author{
Sercan Özkaçmaz ${ }^{1^{*}}$, İlyas Dündar* ${ }^{* 1}$, Leyla Turgut Çoban ${ }^{1}$, İbrahim İlik ${ }^{2}$, Fatma Durmaz ${ }^{1}$, İskan \\ Çallı ${ }^{3}$, \\ ${ }^{1}$ Department of Radiology, Faculty of Medicine, Van Yuzuncu Yil University, 65080, Van, Turkey \\ ${ }^{2}$ Department of Radiology, V an Training and Research Hospital, University of Health Sciences, 65080, Van, Turkey \\ ${ }^{3}$ Department of General Surgery, Faculty of Medicine, V an Yuzuncu Yil University, 65080, Van, Turkey
}

\begin{abstract}
This study aimed to present the radiological findings of survivors from two avalanches within two days in the same valley. This retrospective descriptive study was carried out in two centers after ethics committee approval. The radiological and demographical findings of 47 survivors were screened from two hospital databases. Patients were classified regarding the type of traumatic lesion as well as the lesion sites. A total of 39 traumatic lesions in 22 patients were detected via radiological imaging modalities.

The female/male ratio was $4.8 \%(1 / 21)$ and the mean age was $42.6 \pm 17.1$ years (24-86 years). Among the 39 traumatic lesions, $13(33.3 \%)$ were detected in the extremities ( 4 in the muscles/ligaments, 9 in the bones), $9(23.1 \%)$ in the spine $(5$ transverse, 2 spinous process, and 2 corpus fractures), $9(23.1 \%)$ in the thorax (5 pulmonary contusion, 1 pneumomediastinum, 1 hemothorax, and 2 rib fractures), and $8(20.5 \%)$ in the head (1 subdural hematoma, 5 maxillofacial fractures, and 2 subcutaneous hematomas). There were no abdominal or pelvic lesions detected in this study.

Traumatic lesions can be seen in all systems and organs. Results of this study revealed that spinal and extremity fractures and pulmonary contusions were the most commonly reported traumatic lesions in the included avalanche victims. Muscular injuries were also detected. The use of MRI increases the success of lesion detection in intracranial structures and muscular-ligamentous tissues.
\end{abstract}

Keywords: avalanche disaster, radiology, trauma, computed tomography, magnetic reso nance imaging

\section{Introduction}

Trauma is one of the main causes associated with morbidity and mortality in avalanche victims. However, the cause of death is not known in approximately $1 / 3$ of the patients. Trauma has been reported as the cause of death in $32 \%$ of avalanche victims in whom the cause of death was identified. (1) While any body part can be affected by an avalanche, the most common sites of traumatic lesions are the extremities (bone fractures, muscle injuries), spine (bone fractures), thorax (rib fractures, pulmonary contusions, pneumothorax/hemothorax), and head (contusion, dural hematoma and maxillofacial fractures). The abdomen and pelvis are less frequently affected in avalanche patients. (2)
A small number of literature and imaging findings have been published regarding the injury types of avalanche victims. $(3,4)$ Fast and careful radiological examination is vital for adequate and rapid patient management. This study aimed to improve the radiological management and therefore emergency care by evaluating the radiological findings of the physical traumatic lesions of survivors who were partially or totally buried in two avalanches that occurred within two days in Van an Eastern province of Turkey where avalanches are common. (5)

\section{Materials and Methods}

On February $4^{\text {th }}$, 2020, a minibus and a snowclearing vehicle were buried after an avalanche occurred at approximately 3000 meters above sea

*Corresponding Author: Sercan Özkaçmaz, Van Yuzuncu Yil University, Faculty of Medicine, Department of Radiology, 65080, Campus, Tusba, Van, Turkey

E-mail: sercanozkacmaz@hotmail.com, Phone: +90 (432) 21504 70,Fax: +90 (432) 2168519

ORCID ID: Sercan Özkaçmaz: 0000-0002-9245-0206, İlyas Dündar: 0000-0002-1429-077X, Leyla Turgut Çoban: 0000-0001-7546-6305, İbrahim İlik: 0000-0003-4122-6877, Fatma Durmaz: 0000-0003-3089-7165, İskan Çalli: 0000-0003-1752-2633

Received: 11.05.2021, Accepted: 17.06.2021 
level in a roadway between the city of Van (a city of Eastern Anatolia/Turkey) and Bahçesaray (a town of Van). This avalanche resulted in 5 deaths, 8 survivors, and 2 missing persons. On February 5 th, 2020, a second avalanche occurred at the same location, where the rescue operation was still on-going. As a result of these two avalanches, a total of 42 people died and 84 people were injured. Of these injured patients, 47 were referred to two tertiary training-research and university hospitals while 37 did not require hospitalization. (6)

47 patients who were under the avalanche and admitted to two tertiary care centers were included in the study. 37 people who were not referred to the hospital were excluded from the study. In addition, since we could not reach the autopsy information of 42 people who died under avalanche, they were not included in the study. The medical and radiological imaging data of the 47 survivors were screened from two different hospital databases and radiology department records. The age and gender of the patients were recorded. The computed radiography (CR) was the first imaging modality on all the trauma patients. After CR, computed tomography (CT) and magnetic resonance imaging (MRI) results taken in required patients were interpreted. The radiological reports were reviewed by four radiologists who have $20,10,6$, and 4 years of experience with trauma radiology. All the final decisions was reached with their consensus. CT scans were performed as follows: 30 cranial, 6 neck, 41 thorax, 32 abdomen, 7 pelvic, and 36 spinal. MRI examinations were performed as follows: 19 musculoskeletal, 9 cranial, and 14 spinal.

CT images were obtained via two 16 slice systems (Somatom Emotion 16-Slice; CT 2012 Siemens AG Berlin and Munchen-Germany and Toshiba Alexion ${ }^{\mathrm{TM}} /$ Advance, Toshiba Medical Systems Corporation Nashu, Japan). Two 1.5 Tesla devices (SignaExplorer; GE Healthcare, Milwaukee, Wis. and Magnetom Symphony, Syngo MR B17, Siemens, Germany) were used for MRI imaging.

The radiological traumatic findings of each patient were described. Patients were classified into groups regarding the location of their traumatic lesions, including head, spine, thorax, abdomen, and extremity. Head, spinal, thoracic and extremity lesions were classified into subgroups as intracranial, cranium-maxillofacial bones, soft tissue lesions, corpus fracture, spinous process fracture, transverse process fracture, pulmonary parenchyma, pleura-mediastinum, muscle, ligament and bone lesions respectively. The rates of the lesions at each location were compared with previous studies.

This two-centered retrospective descriptive study was approved by the university ethics committee with a number of 2020/3-21 at the date of 22.05.2020.

Statistical Analysis: Descriptive statistics for continuous variables were expressed as mean, standard deviation, minimum and maximum, while categorical variables were expressed as numbers and percentages.

\section{Results}

Of the 47 patients included in this study (mean age: $37.5 \pm 12.2$ years, age range: $17-75$ years) 22 of this patients (mean age: $40.8 \pm 14.1$ years, age range:24-75 years), had at least one radiological traumatic finding, while 25 had no findings (mean age 34.5 \pm 9.5 years, age range 17-51 years). The mean age of the patients with traumatic radiological findings was higher than that of those without traumatic radiological findings. Among the 47 patients included in this study, 46 were male and one were female (F/M:1/46, 2.2\%). The only female in this study had subdural hematoma, bilateral hemothorax, and left supraspinatus tendon injury (Table 1).

Detailed traumatic radiological findings of avalanche victims and distribution of lesions are summarized in table 1. Musculoskeletal findings $(33 \%)$ were more frequent than extraskeletal findings. The frequencies of the lesions in the head, spine, and thorax were similar. No abdominal or pelvic findings were detected. Fractures were most commonly seen (61.5\%). 24 fractures were found in 15 patients. Most of the patients with lesions had only one finding (15/22, $68.2 \%$ ). There were 2 findings in 1 patient, 3 findings in 4 , and 4 findings in 1 patient. The maximum number of findings ( 6 findings) was detected in a 61 years old male who had cranial subcutaneous hematoma, L2 vertebra corpus fracture, bilateral pulmonary contusion, rib fracture, sternum fracture, and pneumomediastinum. A total of 8 traumatic head lesions (Figure 1) were detected in 6 patients $(6 / 47,12.8 \%)$. A total of 6 patients $(6 / 47,12.8 \%)$ had 9 spinal pathologies (Figure 2). Corpus fracture was not detected in the cervical spine. All of the transverse process fractures were observed in the lumbar spine on the right side. All the spinous process fractures $(n=2)$ occurred in the cervical spine (C4 and $\mathrm{C} 6$ ). 


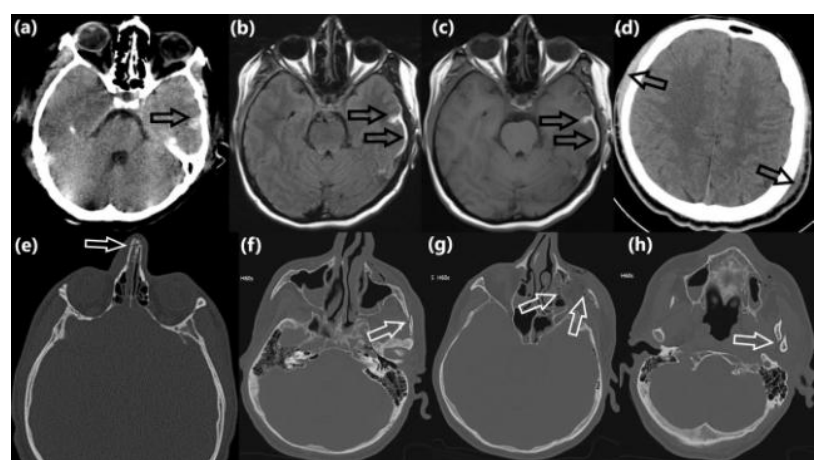

Fig. 1. Traumatic head lesions. An axial non-enhanced CT (a) shows a suspicious hyperdense area in favor of bleeding in the left temporal lobe of the brain, axial FLAIR (b) and non-enhanced T1-weighted MRI (c) show a thin subdural hematoma in the same region respectively. An axial non-enhanced CT (d) shows subcutaneous hematoma in the right frontal and left parietal of the scalp tissue. An axial CT (e) shows a non-displaced fracture of the nasal bone in the bone window. An axial CT (f) also shows the lines of the fracture in the bone window, slightly displaced in the left zygomatic arch, displaced in the lateral and medial walls of the left inferior orbita $(\mathrm{g})$, and displaced in the left mandibular condyle (h) respectively

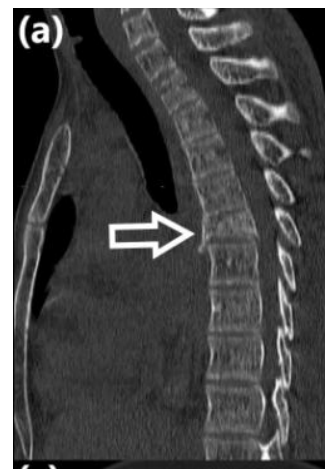

(c)

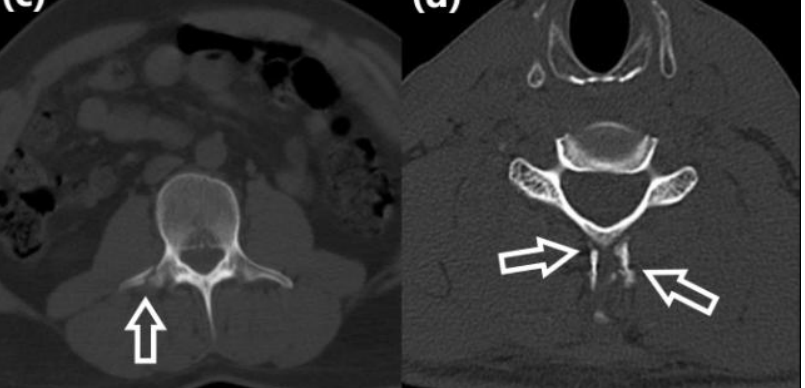

Fig. 2. Traumatic spinal pathologies. Sagittal reformatted (a) and axial (b) CT images demonstrate a T6 vertebra corpus fracture in the bone window. Axial CT image (c) shows a right transverse process fracture in lumbar vertebra. Axial CT image (d) shows a spinous process fractures in cervical vertebra

A total of 9 thoracic traumatic lesions (Figure 3) were detected in 6 patients $(6 / 47,12.8 \%)$. Bilateral pulmonary contusion was seen in 5 patients. The patient who did not have pulmonary contusion had hemothorax.

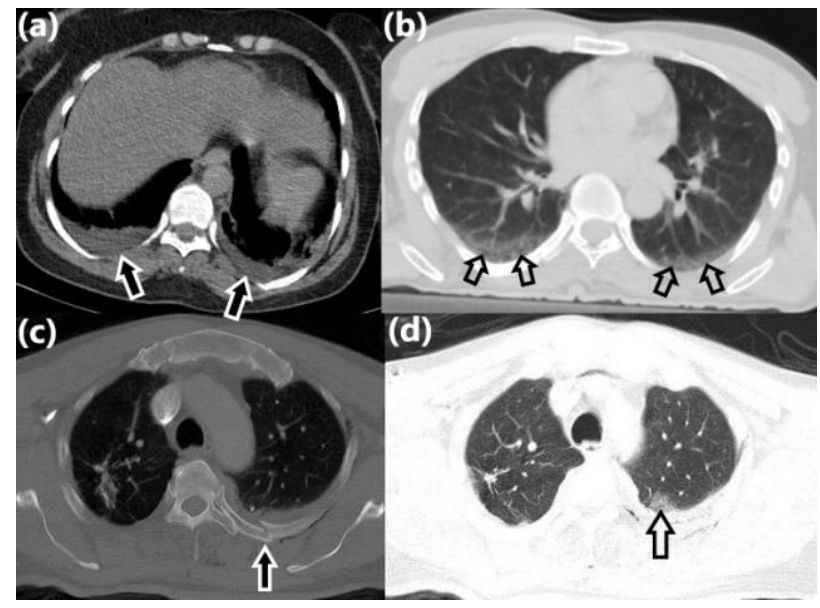

Fig. 3. Thoracic traumatic lesions. An axial nonenhanced thorax CT (a) shows bilateral hemothorax in mediastinal window. An axial non-enhanced thorax CT (b) shows bilateral pulmonary contusion in lung window. Axial non-enhanced thorax CT (c) shows displaced left posterior rib fracture in bone window, and also shows (d) pulmonary contusion in the posterior upper lobe of the left lung in lung window in the same region respectively
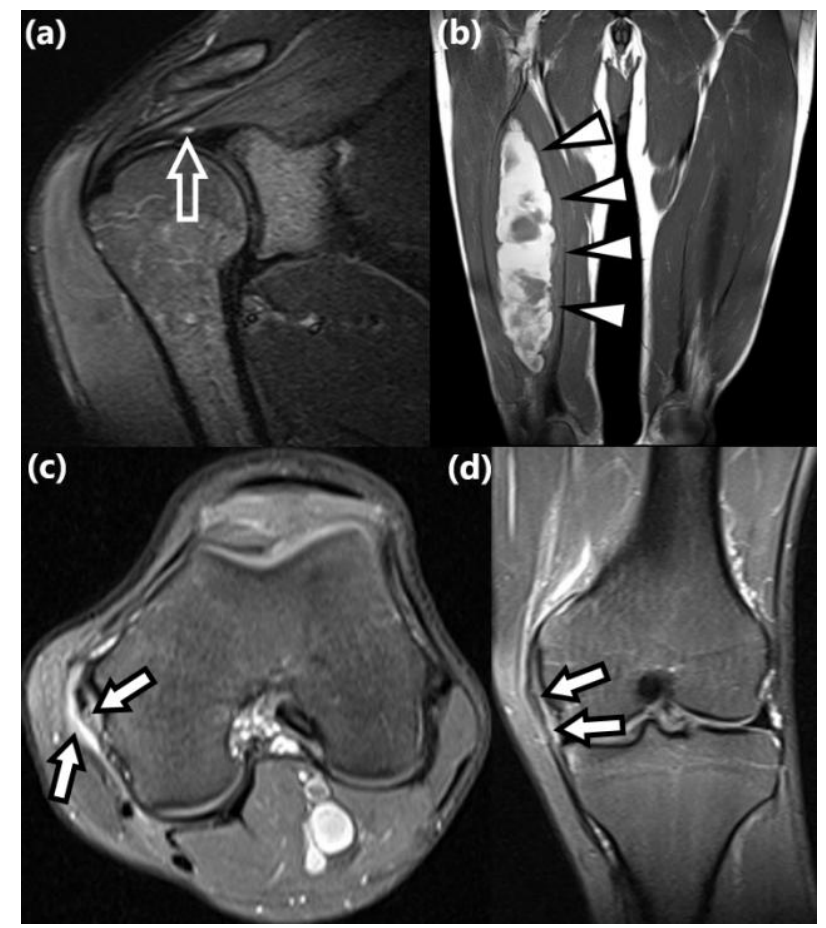

Fig. 4. Extremity muscle and ligaments injuries. A coronal fat-suppressed proton density MR image (a) detects an abnormal bright signal within the supraspinatus tendone compatible with injury in a patient with right shoulder pain. Coronal T1-weighted MR image (b) demonstrates a hematoma with heterogeneous hyperintense signal intensity in vastus intermedius muscle. Axial (c) and coronal fatsuppressed proton density (d) MR images of knee show medial collateral ligament injury and perilesional edema/fluid respectively 


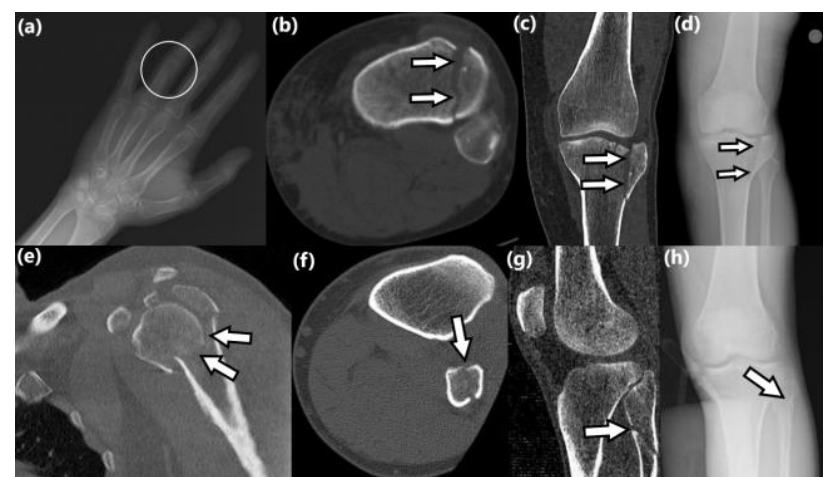

Fig. 5. Extremity bone lesions. A plain radiography (a) shows a distal fracture of proximal phalanx in 4th finger of the right hand. Axial (b), coronal (c) CT images and plain radiography (d) show a slightly displaced linear fracture line extending laterally to the joint space in the left tibia proximal region respectively. A coronal CT image (e) shows a displaced fracture line at the surgical neck level of the proximal left humerus. Axial (f), sagittal (g) CT images and plain radiography $(\mathrm{h})$ show a non-displaced linear fracture in the left fibula proximal region respectively.

A total of 13 traumatic extremity lesions were detected in 11 patients (11/47, 23.4\%). Distribution of the musculoskeletal lesions in the upper and lower extremities are summarized in Table 2. A total of 4 extremity muscle and ligaments injuries (Figure 4) were detected in 4 of our patients $(4 / 47,8.5 \%)$. The frequency of supraspinatus tendon injury was $4.3 \%$ in this study. Regarding the lower extremities, one patient had vastus intermedius hematoma and another one had medial collateral ligament injury and tibia plateau contusion (Figure 4). A total of 9 extremity bone lesions (Figure 5) were identified in 8 patients $(8 / 47,17.0 \%)$. The total number of lesions in the lower extremities (right and left) was markedly higher than that of the upper extremities (9 versus 4, respectively). Lesions in the bones of the lower extremities were seen 3.5 times more frequently than those of the upper extremities ( 7 versus 2 , respectively) (Table 2 ).

\section{Discussion}

Trauma is the second-most common cause of death $(13 \%)$ in avalanche victims. Other causes include asphyxia (most common) and hypothermia. ${ }^{7,8}$ McIntosh et al. ${ }^{9}$ reviewed the autopsy findings of 51 patients killed by an avalanche between 1989 and 2006, and they concluded that $85.7 \%$ of deaths were due to asphyxiation, $8.9 \%$ were due to a combination of asphyxiation and trauma, and $5.4 \%$ were due to trauma alone. 42 victims $(33.3 \%)$ died from the avalanche disaster in Van province. Although it is estimated that most of them died of asphyxia or hypothermia, we could not obtain information about the cause of deaths. Therefore, we could not determine the mortality rates due to trauma.

Holhrieder et al. ${ }^{2}$ reviewed 105 avalanche victims between 1996-2005 and detected 49 significant injuries. Of those 105 patients, $74.3 \%$ patients had no injuries or only minor injuries. Grossman et al. ${ }^{10}$ reviewed a total of 91 individuals who were caught in an avalanche over a 5 year period, and determined that 21 of those patients required medical attention. Among those 21 patients, 12 ultimately died. Eight of the 9 survivors (89\%) and 2 of the 12 deceased patients (16.7\%) had traumatic lesions. A total of 10 of the 91 patients included in that study had trauma $(11 \%)$. In the current study, 25 patients $(53.2 \%)$ had no traumatic radiological findings.

In the study of Grosse et al. (3) traumatic lesions were most common in the extremities (29.3\%) followed by the chest $(22 \%)$, the spine $(19.5 \%)$, the abdomen $(14.7 \%)$, the head $(10 \%)$, and the pelvis (5\%). In the study of Holhreider et al. ${ }^{2}$ traumatic lesions were most commonly located in the extremities $(40.8 \%)$, followed by the spine $(14.3 \%)$, chest $(8.9 \%)$, head $(4.1 \%)$, pelvis $(2.0 \%)$, and abdomen $(2.0 \%)$. In the current study, traumatic lesions were most commonly located in the extremities $(33.3 \%)$, followed by the spine $(23.1 \%)$, chest $(23.1 \%)$, and head (20.5\%). Generally, the results of the current study were consistent with the previous studies above. Contrary to previous studies, the current study did not detect any pelvic fracture or abdominal lesions such as free intraperitoneal fluid, free intraperitoneal air, diaphragmatic rupture, or solid organ injury. We think that in previous studies the intraabdominal or pelvic traumatic injuries were most commonly occurred secondary to fall from high such as mountains. The patients in our study were most frequently affected by complete or partial avalanche burial. Also, some previous studies included the autopsy findings of the dead victims. Pelvic or intraabdominal injuries accompany the other site lesions and usually are seen in more severe traumas which can lead to death. Perhaps if we could evaluate the traumatic lesions of the deads, we would detect intraabdominal or pelvic injuries.

Grosse et al. ${ }^{3}$ reviewed 14 avalanche victims in the Swiss Alps over a two years period who had traumatic injuries. The male/female ratio was 3,67. Holhrieder et al. ${ }^{2}$ reported a male/female ration of 4,25 . In the current study, the male to female ratio was markedly higher (46) as there was 
Table 1. Detailed characteristics of the patients with traumatic radiological findings

\begin{tabular}{|c|c|c|c|c|c|c|c|c|}
\hline Patient & Age & $\begin{array}{c}\text { Gende } \\
\mathrm{r}\end{array}$ & Head & Spine & Thorax & Abdomen & Extremity & $\begin{array}{c}\text { Total } \\
\text { Finding }\end{array}$ \\
\hline 1 & 48 & $\mathrm{~F}$ & $\begin{array}{c}\text { Subdural } \\
\text { hematoma }(5 \\
\mathrm{mm})\end{array}$ & - & $\begin{array}{l}\text { Bilateral } \\
\text { hemoth } \\
\text { orax }(15 \\
\text { mm) }\end{array}$ & - & $\begin{array}{c}\text { Left } \\
\text { supraspinat } \\
\text { us tendon } \\
\text { injury }\end{array}$ & 3 \\
\hline 2 & 28 & $\mathrm{M}$ & $\begin{array}{c}\text { Nasal } \\
\text { fracture }\end{array}$ & $\begin{array}{c}\text { C6 spinous } \\
\text { process } \\
\text { fracture - T6 } \\
\text { vertebrae } \\
\text { corpus } \\
\text { fracture }\end{array}$ & 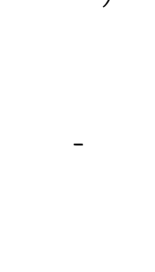 & - & $x^{\prime}$ & 3 \\
\hline 3 & 24 & M & - & $\begin{array}{c}\text { L3 right } \\
\text { transverse } \\
\text { process } \\
\text { fracture }\end{array}$ & - & - & - & 1 \\
\hline 4 & 27 & M & - & - & - & - & $\begin{array}{l}\text { Left tibia } \\
\text { fracture }\end{array}$ & 1 \\
\hline 5 & 26 & M & - & - & - & - & $\begin{array}{l}\text { Right hand } \\
\text { 4. finger } \\
\text { proximal } \\
\text { phalanx } \\
\text { fracture }\end{array}$ & 1 \\
\hline 6 & 33 & M & - & - & $\begin{array}{c}\text { Bilateral } \\
\text { pulmon } \\
\text { ary } \\
\text { contusio } \\
\mathrm{n}\end{array}$ & - & - & 1 \\
\hline 7 & 39 & M & - & $\begin{array}{l}\text { L1-L2-L3 } \\
\text { right } \\
\text { transverse } \\
\text { process } \\
\text { fracture }\end{array}$ & - & - & - & 3 \\
\hline 8 & 26 & $\mathrm{M}$ & - & - & - & - & $\begin{array}{c}\text { Right } \\
\text { supraspinat } \\
\text { us tendon } \\
\text { injury }\end{array}$ & 1 \\
\hline 9 & 34 & $\mathrm{M}$ & - & - & - & - & $\begin{array}{c}\text { Left fibula } \\
\text { proximal } \\
\text { diaphysis } \\
\text { fracture }\end{array}$ & 1 \\
\hline 10 & 25 & $\mathrm{M}$ & $\begin{array}{c}\text { Nasal } \\
\text { fracture }\end{array}$ & - & - & - & $\begin{array}{l}\text { Left tibia } \\
\text { plateau } \\
\text { contusion, } \\
\text { Left knee } \\
\text { medial } \\
\text { collateral } \\
\text { ligament } \\
\text { injury }\end{array}$ & 3 \\
\hline 11 & 34 & $\mathrm{M}$ & - & $\begin{array}{l}\text { C4 Spinous } \\
\text { process } \\
\text { fracture }\end{array}$ & - & - & (-) & 1 \\
\hline 12 & 75 & M & - & L2 right & - & - & - & 1 \\
\hline
\end{tabular}

East J Med Volume:26, Number:3, July-September/2021 


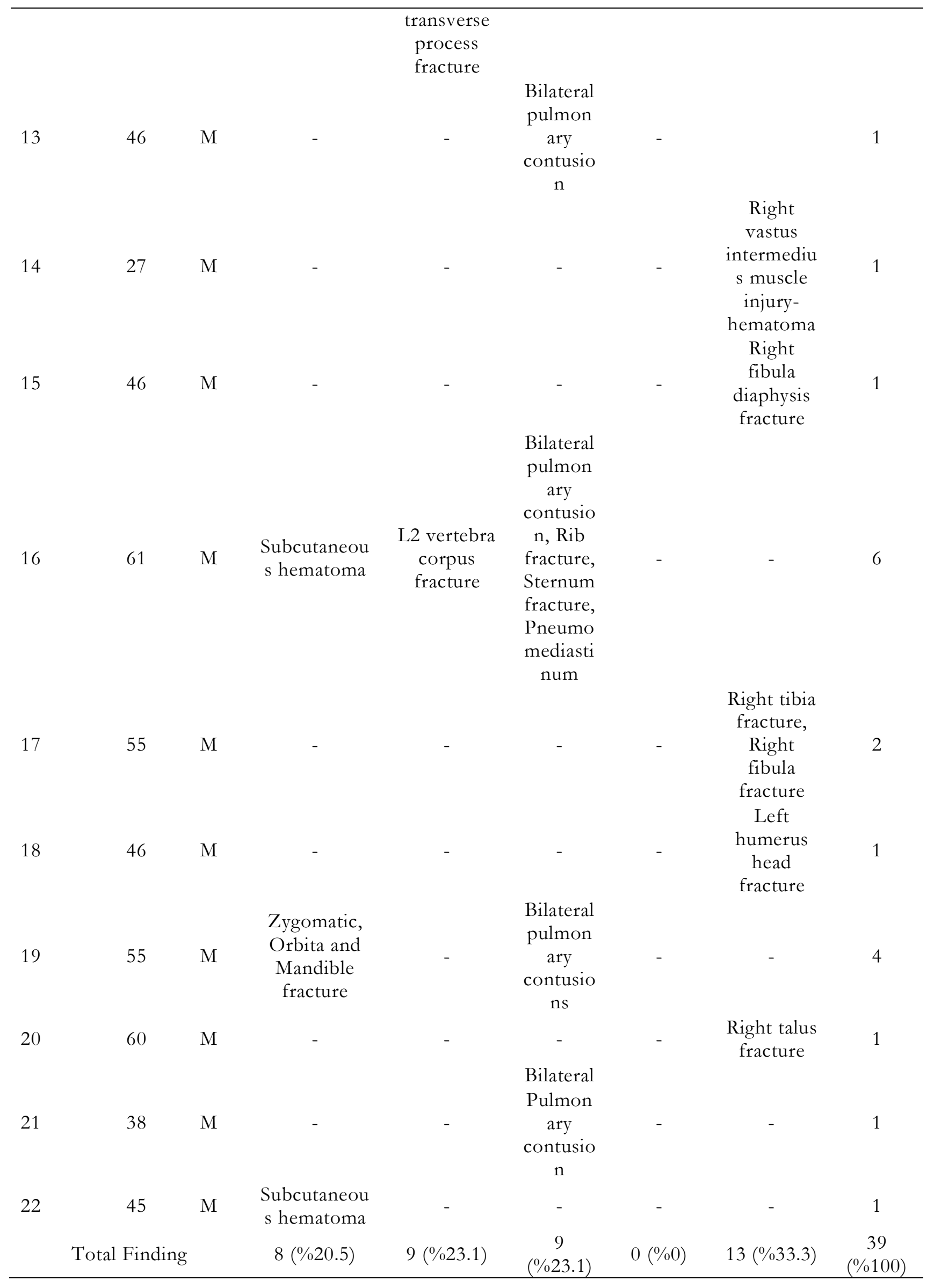


only one female patient. This is because most of the victims in the current study were soldiers, village guardians, and firefighters who were buried by a second avalanche as they were looking for survivors of the first avalanche. (5)

Johnson et al. (11) reviewed that 28 victims died in avalanches in the state of Utah in a 6 years period, and detected that $61 \%(n=17)$ of them had some degree of closed head injury. Stalsberg et al. (8) detected one skull fracture in their autopsy series (8.3\%). McIntosh et al. (9) reported head injury as the most common reason the patients were killed by trauma alone in autopsy series. In the 3 patients killed by trauma alone, they detected skull fracture in one patient. ${ }^{9}$ The autopsy results of the people who died after the avalanche were not available in our study. Grosse et al. (3) reported 2 cerebral contusions, 1 epidural hematoma, and 1 cerebral ischemia (9.8\%). Holhrieder et al. (2) reported 2 cerebral traumas in their patients $(1.9 \%)$. In the current study, the rate of patients with head lesions was $12.8 \%$ and the rate of head lesions among all lesions was $20.5 \%$. The rate of head lesions in the current study were higher than in some previous studies. This may be due to the fact that two patients in the current study had marked cranial subcutaneous hematoma.

Grossman et al. (10) reported one patient with lumbar spinal process fractures among 9 survivors $(11.1 \%)$. Wick et al. (4) reported that $25.5 \%$ (21/91) of their avalanche victims had spine fractures. Holhrieder et al. (2) reported a total 7 spinal fractures (rate of $6.7 \%$ ). In that study, 3 of the spinal fractures were cervical, 3 were lumbar, and one was in the thoracic spine. Similar with that study, the current study saw the least number of fractures in the thoracic spine $(n=1)$. Grosse et al. (3) detected 2 fractures of transverse processes, 3 compression fractures, 1 dislocation fracture, and 2 cervical contusions. Similar with their results ( $\mathrm{T} 9, \mathrm{~L} 2$, and $\mathrm{L} 4$ compression fractures), the compression fractures detected in the current study were in the thoracic and lumbar spine (one in T6 and one in L2 vertebrae). However, we did not identify a dislocation fracture or cervical contusion in the current study. Furthermore, the transverse process fracture rate in the current study is prominent $(n=5)$. It is interesting that in the current study, all of the transverse process fractures were on the right side. In contrast to the study above, the current study had two patients with spinous process fracture, both occurred in the cervical spine (C4 and C6).

Grossman et al. (10) reported rib fractures in 3 of 9 survivors $(33.3 \%)$. Holhrieder et al. (2) detected rib/sternum fracture in $15.2 \%$ of their patients, and hemothorax/pneumothorax in $5.7 \%$ of their patients. In the series of Grosse et al. ${ }^{3}$ there was one sternum fracture and two rib fractures. The study reported pneumothorax in $7.1 \%$ of their patients. In the current study, we detected one hemothorax and one pneumomediastinum (4.3\%). McIntosh et al. (9) reported hemothorax in one patient and rib fracture+diaphragma rupture in one patient among their 3 patients killed by solely trauma. In the current study, one patient had both rib and sternum fractures (2.1\%). Grosse et al. (3) detected 2 pulmonary contusions in their 14 patients $(14.3 \%)$. Grossman et al. (10) reported pulmonary contusion in two survivors $(22.2 \%)$. In the current study, 5 pulmonary contusions $(10.6 \%)$ were seen, and all were bilateral. Stalsberg et al. (8) reviewed the autopsy findings of 12 avalanche victims, and detected rib fracture and hemothorax in one patient $(8.3 \%)$.

Traumatic knee injuries were well-described in avalanche victims in previous studies. Grossman et al. (10) reported anterior cruciate ligament injury in one of 9 survivors $(11.1 \%)$. Grosse et al. (3) observed two medial collateral ruptures $(14.3 \%)$, one lateral collateral ligament rupture $(7.1 \%)$, one posterior cruciate ligament sprain $(7.1 \%)$, and one medial meniscus tear $(7.1 \%)$. The current study also detected one medial collateral ligament injury (2.1\%). However, the current study did not detect any meniscal tears or injuries of the other knee ligaments. One patients in the current study had a vastus intermedius muscle injury $(2.1 \%)$. In contrast to Grosse et al. (3) who did not detect any muscular lesions in the upper extremity, two supraspinatus tendon injuries $(4.3 \%)$ were observed in this study, which have not been well-described in previous studies.

Wick et al. (4) reported humerus fracture in 1.1\%, radius/ulna fracture in $2.1 \%$, femur fracture in $4.4 \%$, tibia/fibula fracture in $11 \%$, and hand bone fracture in $2.1 \%$ of their 94 patients. The study did not detect foot bone fracture. Stalsberg et al. ${ }^{8}$ reported leg fracture in one of 12 avalanche victims $(8.3 \%)$. Grosse et al. (3) reported 1 radius $(7.1 \%), 1$ humerus $(7.1 \%)$ and two lower leg fractures $(14.3 \%)$ in their patients. Grossman et al. (10) reported one radius $(11.1 \%)$ and one femur fracture $(11.1 \%)$ in their 9 survivors. McIntosh et al. (9) reported an upper extremity fracture in one of their three patients killed solely by trauma. The current study observed 5 tibia/fibula fractures $(10.6 \%)$, one tibia contusion $(2.1 \%)$, and one humerus fracture (2.1\%). In addition, the current study detected one 4 th proximal phalanx of the

East J Med Volume:26, Number:3, July-September/2021 
Özkaçmaz et al / Radiological Imaging Findings of Avalanche Victims

Table 2. Distribution of the musculoskeletal lesions in the upper and lower extremities

\begin{tabular}{|c|c|c|c|c|c|c|c|c|c|c|}
\hline & \multicolumn{4}{|c|}{ Upper Extremity } & \multicolumn{4}{|c|}{ Lower Extremity } & \multirow{2}{*}{\multicolumn{2}{|c|}{ Total }} \\
\hline & Right & & Left & & Right & & Left & & & \\
\hline $\begin{array}{l}\text { Musc } \\
\text { le } \\
\& \\
\text { Liga } \\
\text { ment } \\
\text { s }\end{array}$ & $\begin{array}{l}\text { Supraspinatus } \\
\text { tendon injury } \\
\qquad(\mathrm{n}=1)\end{array}$ & $7.7 \%$ & $\begin{array}{l}\text { Supraspinatus } \\
\text { tendon injury } \\
\qquad(\mathrm{n}=1)\end{array}$ & $7.7 \%$ & $\begin{array}{c}\text { Right } \\
\text { vastus } \\
\text { intermediu } \\
\text { s muscle } \\
\text { injury- } \\
\text { hematoma } \\
(\mathrm{n}=1)\end{array}$ & $7.7 \%$ & $\begin{array}{l}\text { Medial } \\
\text { collateral } \\
\text { ligament } \\
\text { injury } \\
(n=1)\end{array}$ & $7.7 \%$ & 4 & $\begin{array}{l}30 \\
8 \%\end{array}$ \\
\hline Bone & $\begin{array}{l}\text { Hand } 4 . \\
\text { phalanx } \\
\text { fracture }( \\
n=1)\end{array}$ & $7.7 \%$ & $\begin{array}{l}\text { Humerus } \\
\text { head fracture } \\
(\mathrm{n}=1)\end{array}$ & $7.7 \%$ & $\begin{array}{c}\text { Fibula } \\
\text { fracture } \\
(\mathrm{n}=2) \\
\text { Tibia } \\
\text { fracture } \\
(\mathrm{n}=1) \\
\text { Talus } \\
\text { fracture } \\
(\mathrm{n}=1)\end{array}$ & $\begin{array}{l}15.3 \% \\
7.7 \%\end{array}$ & $\begin{array}{c}\text { Fibula } \\
\text { fracture } \\
(\mathrm{n}=1) \\
\text { Tibia } \\
\text { fracture } \\
(\mathrm{n}=1) \\
\text { Tibia } \\
\text { contusio } \\
\mathrm{n}(\mathrm{n}=1)\end{array}$ & $7.7 \%$ & 9 & $\begin{array}{l}69 \\
2 \%\end{array}$ \\
\hline Total & 2 & $15.4 \%$ & 2 & $15.4 \%$ & 5 & $38.4 \%$ & 4 & $30.8 \%$ & 13 & $\begin{array}{c}100 \\
\%\end{array}$ \\
\hline
\end{tabular}

hand $(2.1 \%)$ and one talus fracture in the foot $(2.1 \%)$. Consistent with previous studies, in the current study, lower extremity involvement was more common than upper extremity involvement. In addition, tibia and fibula fractures are common in the current study, as seen in previous studies.

The major limitation of the study is the lack of the autopsy findings of the 42 patients dead in these avalanches.

Traumatic lesions can be seen in all the systems and organs, but lesions of the lung parenchyma maxillofacial bones, transverse and spinous processes of the vertebrae, knee-shoulder tissues, and lower extremity bones are most common in avalanche victims. The use of MRI increases the success of lesion detection in intracranial structures and muscular-ligamentous tissues. Also, in avalanche victims extra-axial structures should be carefully examined.

\section{References}

1. Jamieson B, Geldsetzer T. Avalanche Accidents in Canada: Volume 4, 1984-1996: Canadian Avalanche Association Revelstoke BC; 1996.

2. Hohlrieder M, Brugger H, Schubert HM, Pavlic M, Ellerton J, Mair P. Pattern and severity of injury in avalanche victims. High Alt Med Biol 2007; 8: 56-61.
3. Grosse AB, Grosse CA, Steinbach LS, Zimmermann $\mathrm{H}$, Anderson S. Imaging findings of avalanche victims. Skeletal Radiol 2007; 36: 515521.

4. Wick MC, Weiss RJ, Hohlrieder M, Tecklenburg K, Jaschke W, Rieger M. Radiological aspects of injuries of avalanche victims. Injury 2009; 40: 9398.

5. Contributors TNYTJ. Avalanche in Turkey Kills Dozens of Rescuers Responding to Earlier Slide: The New York Times Journal 2020 [Available from:https://www.nytimes.com/2020/02/05/wo rld/europe/turkey-avalanches.html.

6. Contributors W. 2020 Van avalanches: Wikipedia, The Free Encyclopedia.; 2021 [updated 25 January 20214 February 2021]. Available from: https://en.wikipedia.org/w/index.php?title $=2020$ _Van_avalanches\&oldid=1002616964.

7. Rostrup M, Gilbert M. [Avalanche accidents]. Tidsskr Nor Laegeforen 1993; 113: 1100-1102.

8. Stalsberg H, Albretsen C, Gilbert M, Kearney M, Moestue E, Nordrum I, et al. Mechanism of death in avalanche victims. Virchows Arch A Pathol Anat Histopathol 1989; 414: 415-422.

9. McIntosh SE, Grissom CK, Olivares CR, Kim HS, Tremper B. Cause of death in avalanche fatalities. Wilderness Environ Med 2007; 18: 293297.

10. Grossman MD, Saffle JR, Thomas F, Tremper B. Avalanche trauma. J Trauma 1989; 29: 1705-1709.

11. Johnson SM, Johnson AC, Barton RG. Avalanche trauma and closed head injury: adding insult to injury. Wilderness Environ Med 2001; 12: 244-147 